\section{A Large-volume Rhizotron for Evaluating Root Growth Under Natural-like Soil Moisture Conditions}

\author{
Dilma Daniela Silva ${ }^{1}$ and Richard C. Beeson, Jr. \\ University of Florida, Institute of Food and Agricultural Sciences, \\ Mid-Florida Research and Education Center, 2725 S. Binion Road, Apopka, \\ FL 32703
}

Additional index words. rhizotron, root architecture, root growth, rhizosphere, woody plants, Ligustrum japonicum

\begin{abstract}
An experimental system that allows imposition of precise irrigation treatments with easy and quick observations of unrestricted root growth of woody plants was developed. The system mimics natural deep soil percolation and facilitates rapid assessment of large root populations. It was designed to be relatively inexpensive to build so that treatments could be efficiently replicated. Designs for this star-shaped rhizotron were developed and evaluated with the goals of: 1) optimizing volume and shape for minimal physical restriction and use with mature woody plants; 2 ) developing a drainage system comparable to natural deep soils; and 3) facilitating ease, accuracy, and duration of data acquisition. The final design allows efficient root observation, uses a wicktype drainage system to provide a near-uniform profile of soil moisture, and is easily manageable for precise long-term data acquisition. This rhizotron has eight independent viewing/sampling windows and holds $0.16 \mathrm{~m}^{3}$ of soil. An associated lightweight and compact camera positioning frame was developed that facilitates acquisition of digital photographs of soil profiles for time-series assessment of morphological and architectural parameters.
\end{abstract}

Although root growth is central to overall plant performance, the study of natural root development has remained a challenge as a result of the difficulty of observation. Attempts to observe roots over time date back to at least the early 1900s (McDougall, 1916). However, most methods used to study root development are extremely time-consuming and tedious (Calfee, 2003). A rhizotron is a device for non-destructively observing plant roots over time (Garrigues et al., 2006). Root observation facilities described by Karnok and Kucharski (1982), Soileau et al. (1974), and Taylor and Bohm (1976) consisted of underground laboratories with transparent windows. Root observation windows installed in native soil (Gallandt et al., 1990; McDougall, 1916; Metcalfe et al., 2007) were less elaborate but also below soil level. A different approach used transparent tubes (Schoene and Yeager, 2006) or tube-type rhizotrons, which controlled soil temperature (Bland et al., 1990). However, the majority of root development research has relied on narrow observation boxes usually made of Plexiglas (Boukcim et al., 2001; Busch et al., 2006; Devienne-Barret et al., 2006; Garrigues et al., 2006; James et al., 1985; Misra, 1999; Stepniewski et al., 1991; Ugoji and Laing, 2008; Wiese et al., 2005). Although these devices enabled studies on root growth under

Received for publication 27 Apr. 2011. Accepted for publication 27 May 2011.

${ }^{1}$ To whom reprint requests should be addressed; e-maildilma@ufl.edu,dilmadaniela@hotmail.com. greenhouse conditions, soil volume exploited by roots was severely reduced, narrowing applicability of these approaches to seedlings or cuttings. Moreover, root architecture was subjected to artifactual conditions because roots were forced to grow in narrow spaces, forming an unnatural root arrangement. Wright and Wright (2004) developed a star-shaped rhizotron with eight glass panels suitable for greenhouse or field use that overcame many limitations of past approaches. However, it did not fully mimic in-ground conditions. A large rhizotron, designed around concepts of enhanced root observation and tracking strategies, would enable researchers to study growth of whole mature root systems as they develop. Understanding the effects of environmental factors and cultural practices on root growth of mature plants would be of great benefit for applied and fundamental goals ranging from ecology to agriculture, landscaping, and forestry.

The objective of this research was to design and refine an aboveground rhizotron that would enhance observation and recording of undisturbed, natural root growth of woody plants. A primary goal was to mimic in-ground conditions, including minimum physical restrictions and enhanced drainage, the latter being especially valuable for evaluating effects of soil moisture deficits on root growth.

\section{Material and Methods}

Stage 1: Designs for containment and observation ports. A prototype rhizotron was constructed in May 2006 to evaluate different materials and designs for root observation and sampling. The shape was that of a star with four arms radiating from a central rectangular frame (Fig. 1). This star-shaped rhizotron enclosed $0.18 \mathrm{~m}^{3}$ of soil, measured $2.1 \mathrm{~m}$ across, and was $0.31 \mathrm{~m}$ deep at the tip of the arms. The central frame was $0.25 \times 0.25 \times 0.37 \mathrm{~m}$ tall. The bottom of each arm was made from expanded white polyvinylchloride (PVC) board ( $6 \mathrm{~mm}$; Kommerling Inc., Huntsville, AL), which was sealed along the edges with silicone caulk (DAP Products Inc., Tipp City, $\mathrm{OH}$ ) and was sloped toward the center frame to facilitate drainage and to reduce perched water tables common in flat-bottomed containers (Bilderback and Fonteno, 1987; Spomer, 1980). The bottom of the center frame consisted of a plastic mesh $(12.5 \mathrm{~mm}$ square) over which woven groundcover (Lumite Inc., Gainesville, GA) was placed to support the substrate. The frame of this prototype rhizotron was welded from angleiron strips [L-shaped cross-sections $(18 \times$ $18 \mathrm{~mm}$ ) of 3-mm iron] with narrower width $(12.5 \times 12.5 \mathrm{~mm})$ at the top of the frame to facilitate transplanting root balls (typically 11.4 L from standard nursery containers). To facilitate observation, the rhizotron was supported by four legs $(60 \mathrm{~cm})$ at the tip of each arm.

Each lateral side of an arm of the rhizotron was used to evaluate different systems for non-disruptive visualization of roots while holding substrate in place. Four different viewing port designs were evaluated: 1) a single door the length of a lateral attached by two brass hinges (Fig. 1A); 2) a single sliding panel the length of a lateral (Fig. 1B); 3) two independent doors each held by two brass hinges (Fig. 1C); and 4) a side panel with two smaller doors attached to the panel (Fig. 1D). For some configurations, $12.5-\mathrm{mm}$ square wire mesh was placed laterally to hold substrate in place. Two materials were evaluated for doors: 2.2-mm clear Plexiglas and 8-mm Thin-wall polycarbonate (Lexan; General Electric, Fairfield, CT). In addition, different methods were tested for sealing doors to avoid moisture loss and to remain closed.

After construction, a Ligustrum japonicum Thunb. from an 11.4-L container was transplanted into the rhizotron using a commercial substrate composed of Canadian sphagnum peatmoss, processed pine bark, perlite, vermiculite, starter nutrients, wetting agents, and dolomitic limestone (Mix \#4; Conrad Fafard Inc., Agawan, MA). Irrigation was supplied daily with three bubbler emitters per arm (Model Shrubbler $360^{\circ}$; Antelco, Longwood, FL). Rhizotron arms were covered with opaque woven groundcover (Lumite Inc.) to exclude light. Groundcover was removed from the arms only for root recording and monitoring. Roots were traced using permanent markers on Plexiglas door models. For polycarbonate doors, transparent plastic sheets $(20 \times 25 \mathrm{~cm})$ were placed on the side of a soil profile for tracing roots.

Stage 2: Designs for drainage systems allowing natural soil profiles and substrate 
temperature evaluation. Twenty-four rhizotrons were produced in late 2006 based on results from Stage 1. The final design of rhizotrons retained the $0.6-\mathrm{m}$ air gap between the plastic mesh and the ground below. This resulted in unacceptable levels of perched water tables within the rhizotrons (data not shown). In July 2007, two additional drainage systems were compared with the original design for their ability to reduce or eliminate the was better simulation of in-ground moisture characteristics.

The hanging water column system (Fig. 2B) was designed to remove excess water from the substrate to a set tension level. For this, a 24-cm diameter polyethylene funnel was installed and sealed with silicone caulk (DAP perched water table. The goal of these systems

Products Inc.) underneath the center frame and filled with medium texture sand (TavaresMillhopper fine sand) of a finer texture than the substrate above (Mix \#4; Conrad Fafard Inc.). A 60-cm length of Tygon R-3603 laboratory tubing (6.3 $\mathrm{mm}$ internal diameter) was attached to the bottom of the funnel. The lower end was elevated $7 \mathrm{~cm}$ to establish a hanging water column.

The wick system (Fig. 2C) consisted of a superabsorbent felt covered with perforated black polyethylene landscape fabric (WeedBlock; Easy Gardner Products, Inc., Waco, TX) installed under the substrate. The felt extended into the air below the bottom of the center frame $40 \mathrm{~cm}$. The felt was the bottom layer of the capillary system Aquamat ${ }^{\circledR}$ (Soleno Textiles Inc., Laval, Quebec, Canada).
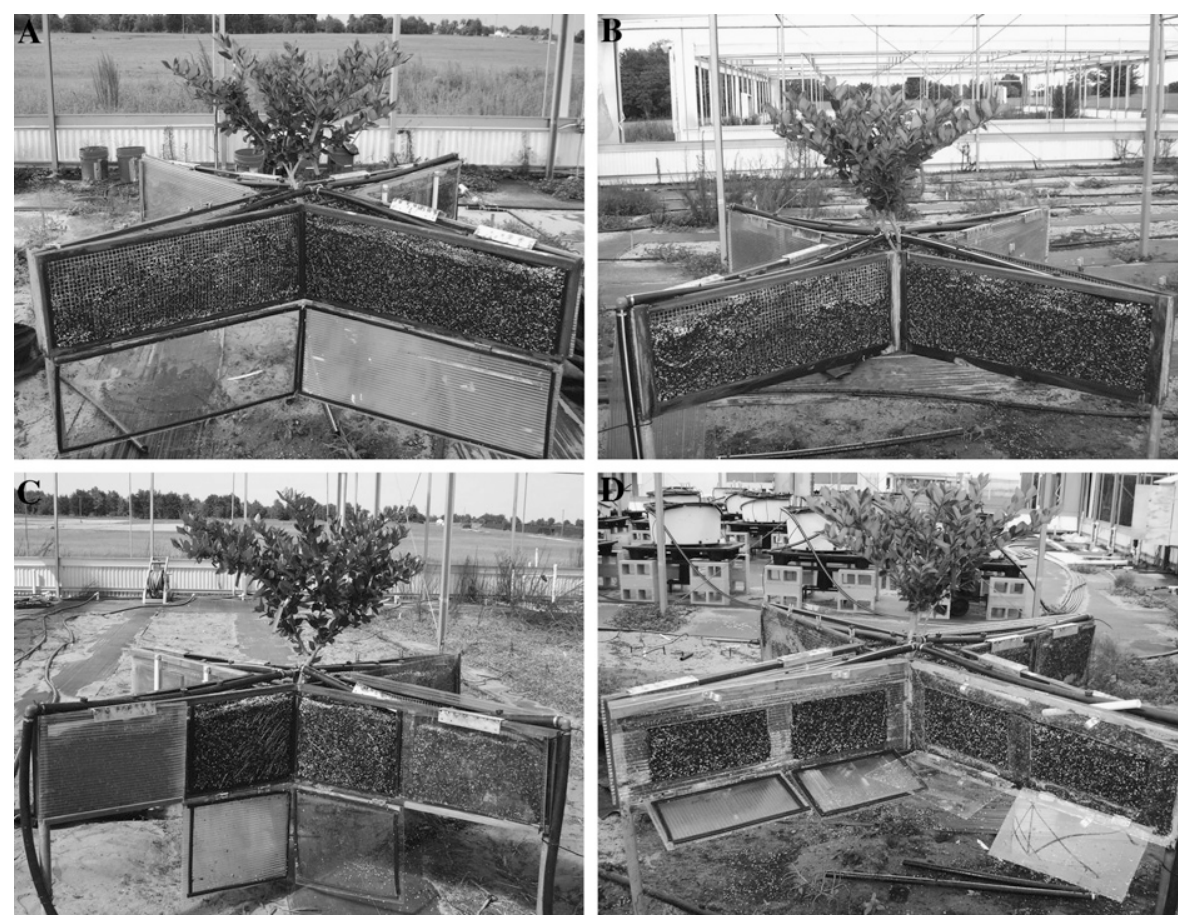

Fig. 1. Prototype rhizotron with Ligustrum japonicum 2 months after transplanting into rhizotron. Doors of rhizotron open only for demonstration. (A) Single door. (B) Sliding panel. (C) Double doors. (D) Side panel with two doors.
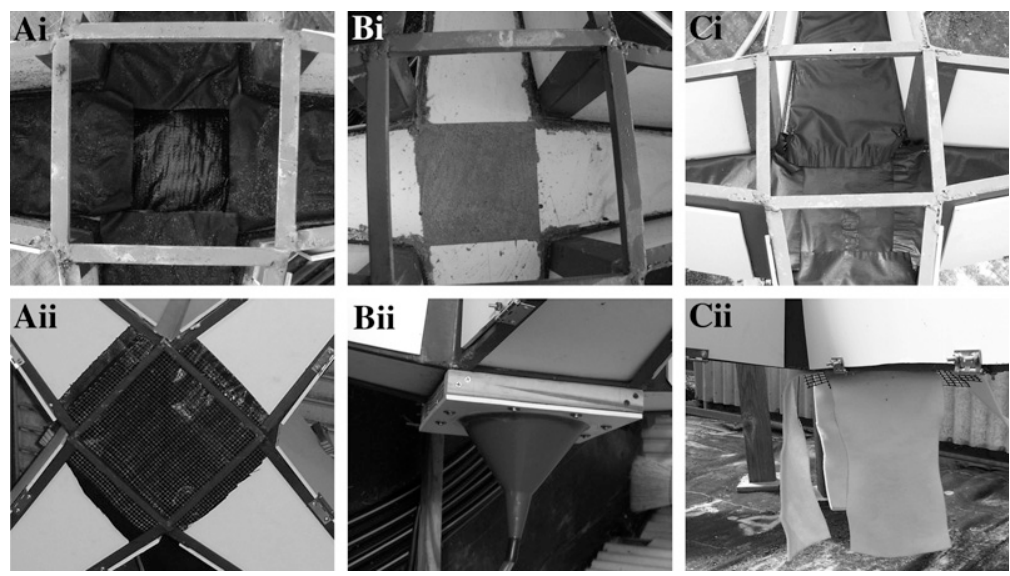

Fig. 2. Drainage systems tested on rhizotrons: (i) top view and (ii) bottom view. (A) Simple mesh. (B) Hanging water column. (C) Wick system.
The WeedBlock layer was added to prevent roots from growing into the felt below.

Rhizotrons were filled with a commercial substrate (Mix \#4; Conrad Fafard Inc.). Soil moisture sensors, EC-5 $\mathrm{ECH}_{2} \mathrm{O}$ probes (Decagon Devices Inc., Pullman, WA), were used to characterize soil moisture profiles. Sensors were connected to a data logger (CR10X; Campbell Scientific, Inc., Logan, UT) through an AM16-32 multiplexer (Campbell Scientific, Inc.). Before use, $\mathrm{ECH}_{2} \mathrm{O}$ probes were calibrated for the substrate used against a time domain transmissometry sensor (Digital TDT $^{\mathrm{TM}}$, Model ACC-SEN-TDT; Acclima, Inc., Meridian, ID). The Digital $\mathrm{TDT}^{\mathrm{TM}}$ was placed horizontally on $8 \mathrm{~cm}$ of rhizotron substrate in the center of a $0.6-\mathrm{m}$ polyvinyl ring made from landfill liner material placed directly on porous ground cloth covering a native sand soil base inside the greenhouse. The ring was $30 \mathrm{~cm}$ tall with the white side facing outward. $\mathrm{ECH}_{2} \mathrm{O}$ probes were placed horizontally around the TDT separated by at least $5 \mathrm{~cm}$. Additional substrate was added and lightly compacted to $\approx 5 \mathrm{~cm}$ of additional depth. Water from an onsite well (electrical conductivity less than $0.2 \mathrm{dS} \cdot \mathrm{cm}^{-1}$ ) was gently added to the substrate to a depth of $\approx 10 \mathrm{~cm}$. Data were collected from probes every $30 \mathrm{~min}$ for $13 \mathrm{~d}$ until percent volumetric water content (\%VWC) had declined to $\approx 20 \%$. Data from each probe was analyzed by regression (Microsoft Office Excel 2007; Microsoft Corp., Redmond, WA) against \%VWC recorded by the TDT to obtain best fit lines (quadratic).

The three drainage systems were evaluated for $12 \mathrm{~d}$ (four irrigation cycles at 3-d intervals) with three rhizotron replications for each drainage system. Each rhizotron replication had three $\mathrm{ECH}_{2} \mathrm{O}$ probes installed to monitor substrate moisture: at the center of one arm, the center of the center frame, and bottom of the center frame. Volumetric water content was analyzed as a $3 \times 3$ factorial with drainage system and probe position as treatments with three replications using SAS (Version 9.1; SAS Institute, Cary, NC).

In July 2007, T-type thermocouples were placed to monitor daily variations of substrate temperature. Two shielded thermocouples monitored air temperature. Four thermocouples were installed $1 \mathrm{~cm}$ behind different doors to monitor substrate temperature.

Quantifying root growth. Ten clonal $L$. japonicum plants grown in 3.8 -L containers were selected for uniformity from a local nursery (Jon's Nursery, Eustis, FL) and transplanted singly into rhizotrons filled with a commercial substrate (Mix \# 4; Conrad Fafard Inc.) in the spring of 2009. Rhizotrons were located in the same open-sided greenhouse with a double polyethylene roof, under natural light, located in Apopka, FL, as used in the experiments described previously. Entire rhizotrons were irrigated daily until saturation for $41 \mathrm{~d}$ for plant acclimatization. Thereafter, irrigation was withheld for $6 \mathrm{~d}$ before the start of irrigation treatments. Treatments consisted of two irrigation frequencies: a long wetting and drying cycle (irrigated once a week for 10 min with $12 \mathrm{~L}$ of water) and 
a short wetting and drying cycle (irrigated every other day for $5 \mathrm{~min}$ with $6 \mathrm{~L}$ of water) with five replications each. Irrigation was initiated at 1930 HR each time. Growth parameters were measured weekly until final harvest, $159 \mathrm{~d}$ after transplant. These data are reported elsewhere. One week before harvest, digital photographs of each observation port of the 10 rhizotrons were taken with a Kodak EasyShare Z712 IS with a 36-432 mm optical zoom len (Eastman Kodak, Rochester, NY). Root images from each observation port were measured using WinRHIZO Tron software (Regent Instruments, Quebec, Canada). Length of roots of different diameter classes was summed for each rhizotron and the values were used together with specific root length to calculate weight of new roots visible on observation ports. Specific root length $\left(\mathrm{cm} \cdot \mathrm{g}^{-1}\right)$ was determined to evaluate the percentage of new roots visible on rhizotron observation ports.

Calibration of digital pictures was accomplished with four independent sets of roots harvested from market-sized ligustrum growing in 11-L containers at a local nursery (Spring Hill Nursery, Ocoee, FL). These roots were rinsed with water and positioned on a light-colored background for digital photograph recording. Immediately after the photographs, length and diameter (in $0.5-\mathrm{mm}$ increments) of each root was obtained by analyzing photographs with WinRHIZO Tron MF. Roots were hand-separated by diameter class and ovendried at $65{ }^{\circ} \mathrm{C}$ until constant dry mass was obtained. Specific root length was calculated for each diameter class.

Plants in rhizotrons were harvested $159 \mathrm{~d}$ after transplant. Roots were divided between those that developed after transplant (referred as new roots) and roots from the root ball present at transplant (referred to as old roots). Old and new roots were cleaned using a root separator (Silva et al., 2011) and oven-dried at $65^{\circ} \mathrm{C}$ until constant dry mass was obtained. Percentage of visible roots was calculated by the formula:

$\%$ visible roots $=[$ (total length of roots of a diameter class visible from 8 sides/specific length of a diameter class)*100]/new root dry mass

Percentages of visible roots from the two treatments were compared using a completely randomized design with five replications. Data analysis was accomplished using SAS (Version 9.1; SAS Institute, Cary, NC).

Camera positioning frame. A camera positioning frame (Fig. 6) was developed to hold the camera at a constant distance and location for time-series digital recording of root growth. The positioning frame was constructed using a $2.8 \times 2.8 \times 61-\mathrm{cm}$ magnetic bar (Ningbo Ketian Magnet Co., Zhejiang Province, China) that could be centered on the top edge of each lateral of an arm of the rhizotron. From the center of this magnetic bar, an aluminum bar $(2.5 \times 0.5 \mathrm{~cm})$ was bent into a $\mathrm{C}$-shape with $90^{\circ}$ turns at the distal ends so that it braced the frame against opened PVC doors. The distance of the arm to the vertical leg of the "C" was $0.63 \mathrm{~m}$. A $12-\mathrm{mm}$ square aluminum bar $16 \mathrm{~cm}$ long was attached perpendicularly to the vertical portion of the " $\mathrm{C}$ " using a single screw within a $10-\mathrm{cm}$ section of $1.8-\mathrm{cm}$ aluminum $\mathrm{C}$-channel so that it would pivot from one side of the vertical leg to the other within the C-channel. The vertical position of the pivot arm was such that optical center of the camera would point directly at the vertical face of rhizotrons. The camera was connected to the perpendicular bar using one screw enabling the camera to face a rhizotron from left or right.

\section{Results and Discussion}

Rhizotron design and root monitoring. After 5 months of growth under non-limiting soil moisture in the prototype rhizotron, $L$. japonicum had expanded roots only $75 \%$ of the length of a rhizotron's arm. It was concluded that arms could be shortened to reduce cost and overall floor space while still achieving research goals. The final rhizotron's cen- tral frame was $0.25 \times 0.25 \times 0.35 \mathrm{~m}$ tall, and laterals were decreased from $0.93 \mathrm{~m}$ to $0.78 \mathrm{~m}$ in length. This reduced the overall width of a rhizotron from $2.1 \mathrm{~m}$ to $1.76 \mathrm{~m}$. The slope of the bottom of each arm increased slightly $(6.4 \%$ to $6.6 \%)$. The framework of the final rhizotron was constructed with $1.61-\mathrm{mm}$ thick galvanized sheet metal (Fig. $3 ; 5 \times 3.8 \times 5-\mathrm{cm}$ U-shaped arm cap, $5 \times 5$-cm V-shaped interior angle, and $5 \times 2-\mathrm{cm}$ L-shaped arm top crosspiece). Only the top and bottom squares of the center frame $(25 \times 25 \mathrm{~cm})$ were made of 2-cm flat iron strips (Fig. 3). The pieces were welded and painted to avoid corrosion. Rhizotrons were raised $0.6 \mathrm{~m}$ above the ground by wooden legs. The final rhizotron design (Fig. 4) enclosed $0.16 \mathrm{~m}^{3}$ of soil, measured $1.76 \mathrm{~m}$ across, $0.30 \mathrm{~m}$ deep in the tip of the arms, and $0.35 \mathrm{~m}$ deep in the center.

Of the door types evaluated, a single door (Fig. 1A) attached with two hinges proved most effective. It allowed easiest access for root observation, recording, and measurement of roots. Once wet, the substrate was stable and remained in place when doors were open. The wire mesh on the side of arms was found to be unnecessary. Although offering good stability, sliding panels (Fig.
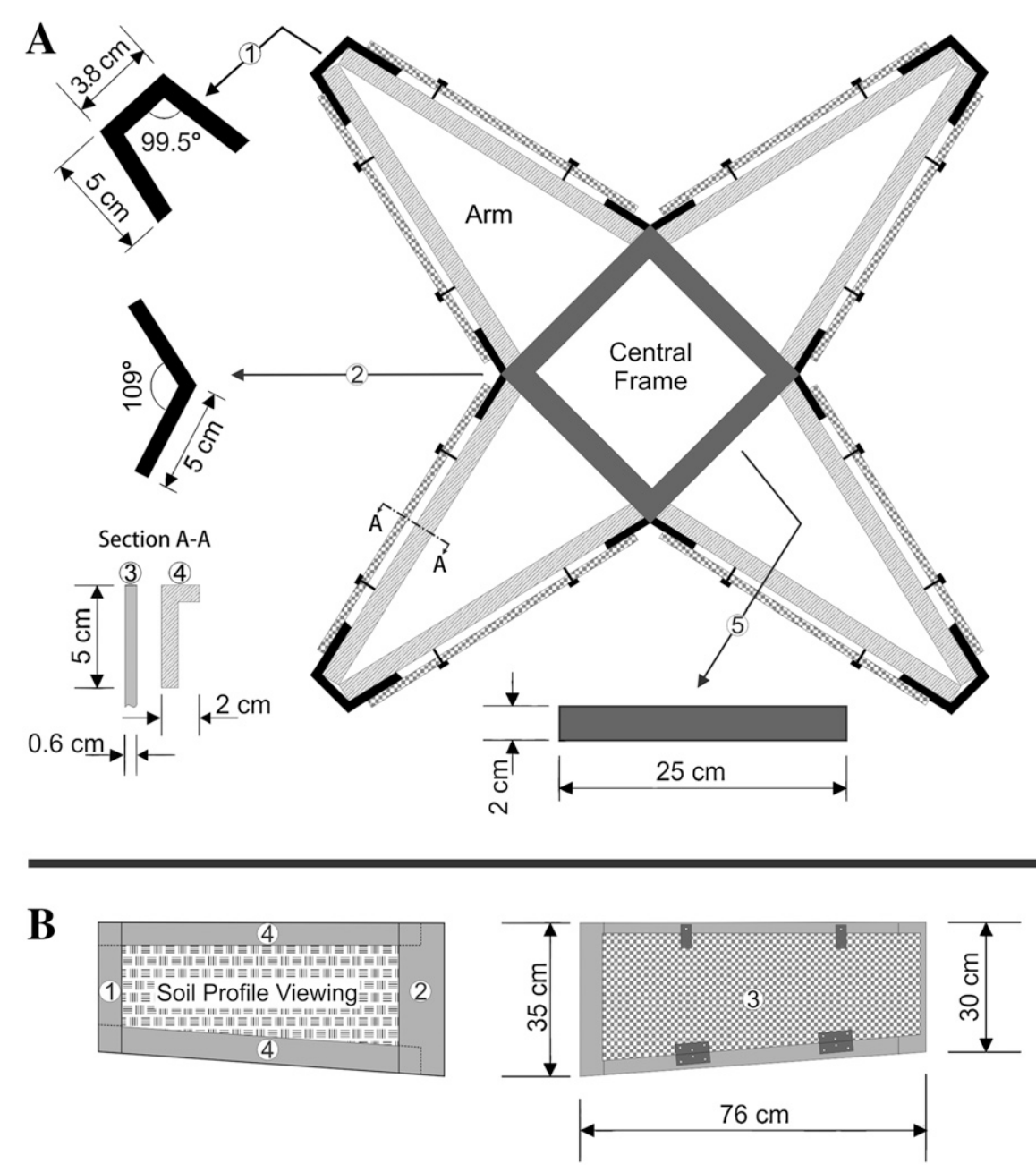

Fig. 3. Schematic diagram of a rhizotron. (A) Top view with details of materials used on construction: (1) arm end cap, (2) interior angle, (3) expanded polyvinyl chloride door, (4) top and bottom arm crosspieces, and (5) flat iron used for the bottom and top of central frame. (B) Side view of side arm without door and with closed door (left and right, respectively). 
1B) were not practical. When slid open, friction crumbled the substrate into the tracks causing subsequent mechanical problems. The center post, used to help seal double doors (Fig. 1C), obscured roots and made recording root growth by digital images troublesome. Moreover, opening and closing two doors for root observations was more time-consuming. Likewise, side panels with two doors (Fig. 1D) were more difficult to operate and offered no advantages.

Both the Plexiglas and thin-wall polycarbonate materials evaluated in the prototype doors were rigid enough for use; however, roots were observed with much more detail with open doors, thus negating the need for transparency. Although Plexiglas has been the material of choice for many researchers, moisture accumulation inside the panels can make observation through them difficult. An additional problem associated with clear Plexiglas was glare, which makes digital photographs of roots unfeasible. Thin-wall polycarbonate was lightweight and readily accessible. However, it did not allow root observation through doors and permitted light penetration to roots unless the system was covered. After considering other available materials for constructing the observation ports, the white 6-mm expanded PVC board (Kommerling Inc.) was used. Expanded PVC was inexpensive, waterproof, and sufficiently rigid to retain the lateral shape of rhizotron arms when filled with the substrate. Being opaque, it eliminated the need for additional light-blocking material. The white color of the board also reflected radiation, thus aiding heat management. Expanded PVC board was used to build the door panels of the final designed rhizotron. The difference in temperature between substrate immediately next to the PVC door and air varied between -4.5 and $4{ }^{\circ} \mathrm{C}$ during the course of the day. Substrate temperature varied less than air temperature (Fig. 5), being cooler during the day and warmer during the night. Doors were held in a closed position by two $7-\mathrm{cm}$ wooden buttons attached to the frame with machine bolts.

To limit evaporation from the substrate surface, a perforated black polyethylene landscape fabric (WeedBlock) was cut to fit and placed on top of the substrate. No roots grew through the landscape fabric placed on top of the substrate. Irrigation was provided by placing a spray stake (Model green 22500001120; Netafim Irrigation, Inc., Fresno, CA) at the tip of each arm pointing inward. The angle created by the irrigation spray approximated the internal angle on arms. The four sprays of water slightly overlapped at the center, providing uniform coverage.

The eight observation ports made possible the visualization of $2.8 \%$ of roots developed by $L$. japonicum plants during the growing period (Table 1). Moderate water stress did not affect root visualization (Table 1); neither did it affect root distribution within diameter classes. Considering the outer $0.5 \mathrm{~cm}$ of soil, the final designed rhizotron exposes 0.00594 $\mathrm{m}^{3}$ of soil or $3.7 \%$ of the total volume. Because

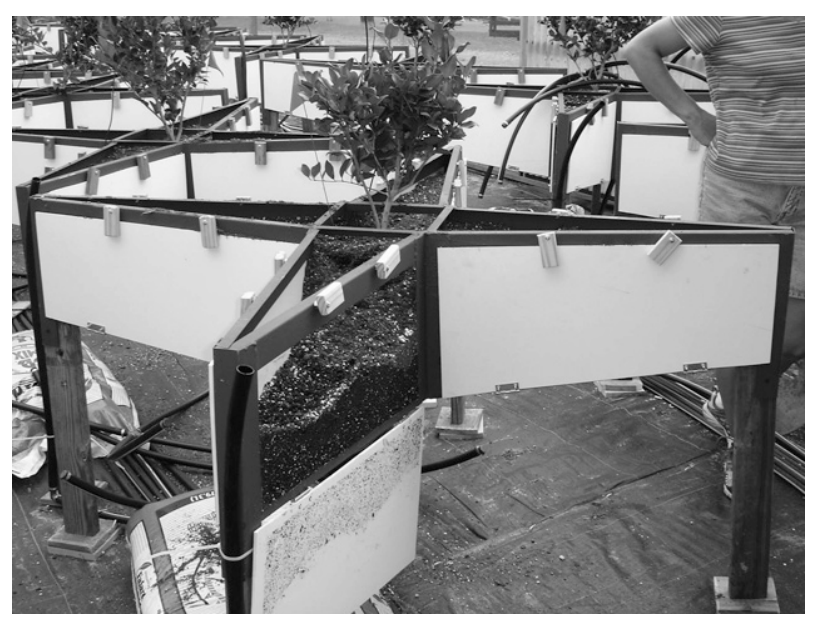

Fig. 4. One-year-old Ligustrum japonicum transplanted in a rhizotron; the window is open just for demonstration.

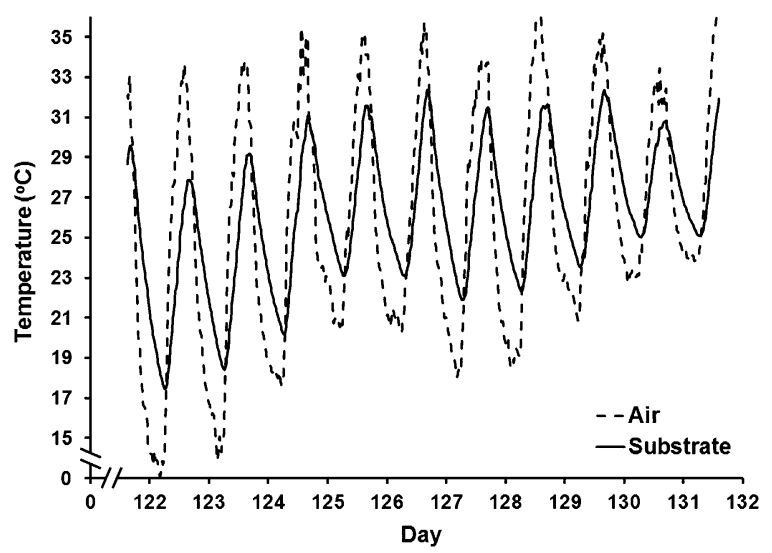

Fig. 5. Mean temperature of air and substrate immediately behind polyvinyl chloride doors (substrate: means of four thermocouples; air: means of two thermocouples).

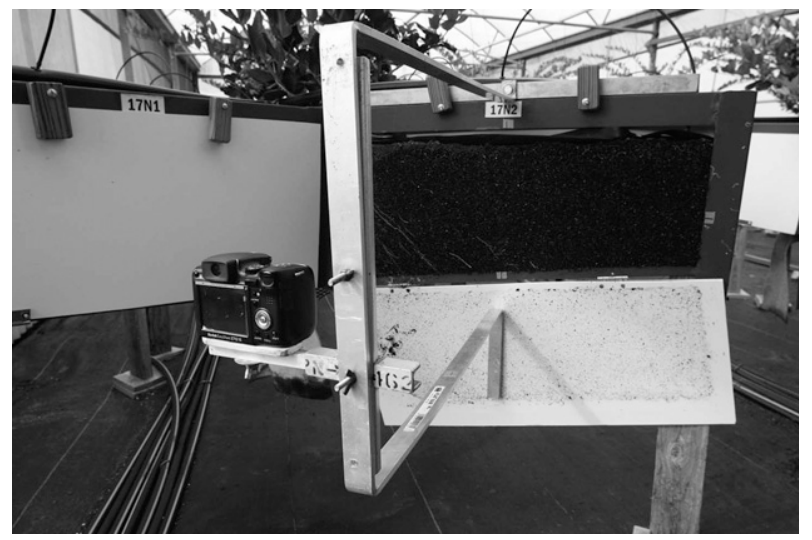

Fig. 6. Camera positioning frame used to take pictures mounted on rhizotron.

Table 1. Specific root length, dry mass, and percentage of total new roots visible in all eight rhizotron observation ports. ${ }^{z}$

\begin{tabular}{lcrr}
\hline Root diam $(\mathrm{mm})$ & Specific root length $\left(\mathrm{cm} \cdot \mathrm{g}^{-1}\right)$ & Dry mass $(\mathrm{g})$ & Percent of total \\
\hline $0.0<\emptyset \leq 0.5$ & 3247.7 & $0.003^{\mathrm{y}}( \pm 0.004)$ & $0.004^{\mathrm{y}}( \pm 0.004)$ \\
$0.5<\emptyset \leq 1.0$ & 1657.3 & $0.738( \pm 0.311)$ & $0.831( \pm 0.264)$ \\
$1.0<\emptyset \leq 1.5$ & 662.2 & $1.112( \pm 0.295)$ & $1.299( \pm 0.296)$ \\
$1.5<\emptyset \leq 2.0$ & 332.8 & $0.571( \pm 0.260)$ & $0.657( \pm 0.318)$ \\
Total & & $2.424( \pm 0.682)$ & $2.790( \pm 0.548)$ \\
\hline
\end{tabular}

${ }^{\mathrm{z}}$ Masses and percentages were pooled between treatments (short and long wetting and drying cycles) when there was no significant difference between means at $P \geq 0.05$ (Fisher's least significant difference). SDS are given in parentheses.

${ }^{\mathrm{y}}$ Means of 10 repetitions. 
roots did not reach the tips of rhizotron, the $2.8 \%$ of roots exposed is within reasonable limits and suggests good distribution of roots throughout the soil. Moreover, total length and total volume of roots visible on observation windows was similar in all directions (Table 2).

The camera positioning frame was lightweight, compact, and easy to use. The flexibility of locations for the camera enabled a shorter distance from the soil profile to the camera and resulted in high resolutions and close spacing between rhizotrons. Initially,

Table 2. Mean total length and total volume of new roots visible in all eight rhizotron observation ports. $^{\mathrm{z}}$

\begin{tabular}{lcc}
\hline & Total length $(\mathrm{cm})$ & Total volume $\left(\mathrm{cm}^{3}\right)$ \\
\hline North & $557.4^{y}( \pm 229.7)$ & $4.8( \pm 2.0) \mathrm{ab}$ \\
West & $486.7( \pm 220.5)$ & $4.3( \pm 1.7) \mathrm{b}$ \\
South & $641.8( \pm 352.1)$ & $6.3( \pm 3.2) \mathrm{a}$ \\
East & $481.3( \pm 151.4)$ & $4.7( \pm 1.4) \mathrm{ab}$ \\
Total & $2167.2( \pm 707.1)$ & $20.2( \pm 5.6)$ \\
\hline
\end{tabular}

${ }^{\mathrm{z} L e n g t h s}$ and volumes were pooled between treatments (short and long wetting and drying cycles) when there was no significant difference between means at $P \geq 0.05$ (Fisher's least significant difference). SDS are given in parentheses.

${ }^{\mathrm{y}}$ Means of 10 replications. only a single image was required to encompass the early root growth. The second picture per profile (from the distal half of the profile) was necessary only on later stages, after roots had grown past the halfway mark. Serial photography can allow for further analyses of morphological characteristics, various root orders, and root geometry (Wiese et al., 2005). However, for accurate analysis, serial photographs must be taken at exactly the same location and distance each time.

Drainage system and substrate temperature. The simple mesh drainage system (Fig. 2A) was unable to remove excess water efficiently. In this system, the substrate at the bottom of rhizotron was consistently at a significantly higher moisture level than the other two locations, indicating impeded drainage. For example, the bottom, arm, and center positions averaged $52.7 \%, 39.4 \%$, and $27.9 \%$ VWC, respectively, $2 \mathrm{~h}$ before irrigation $(70 \mathrm{~h}$ after the last irrigation; Fig. 7A). Moreover, substrate located in arms remained at considerably higher moisture levels than that in the center of the rhizotron.

The hanging water column system (Fig. 2B) worked relatively well at draining water (Fig. 7B). This system, however, was also not

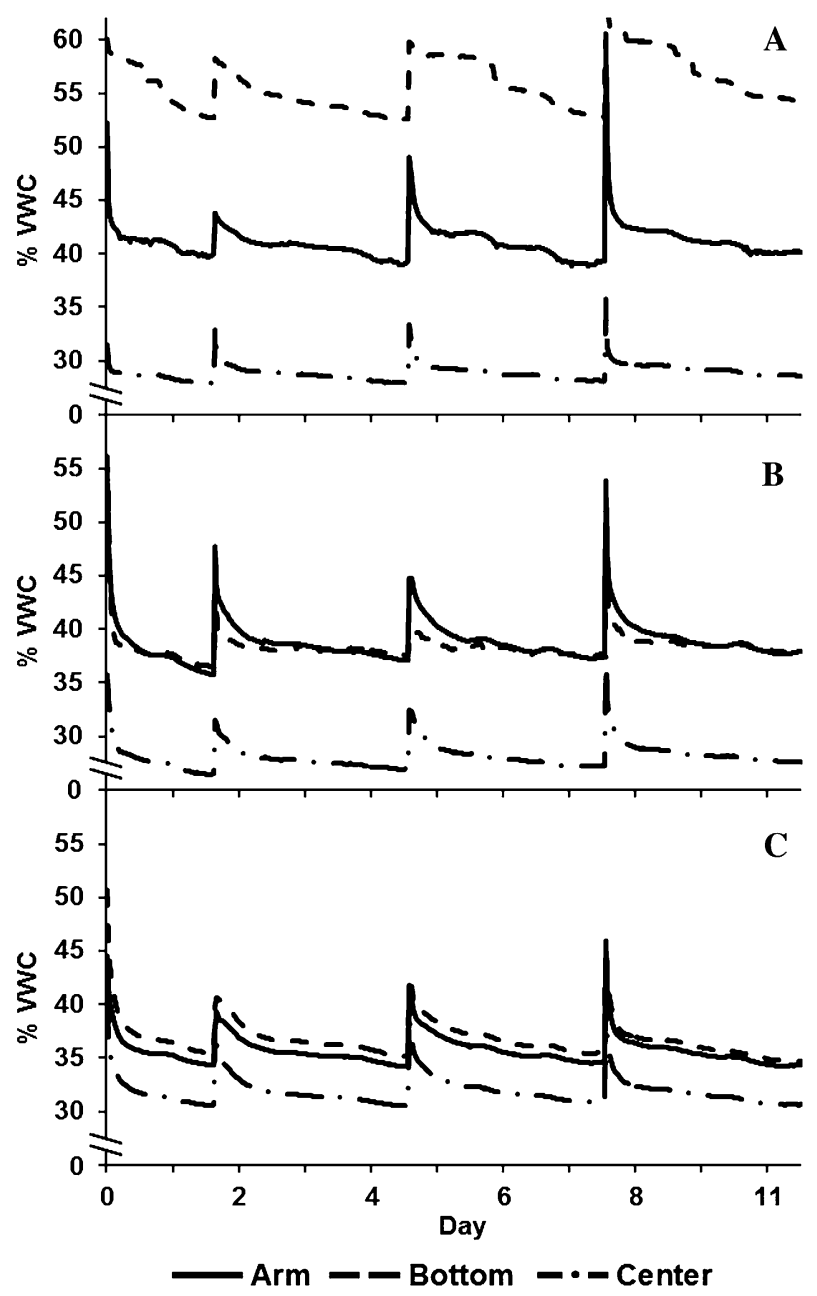

Fig. 7. Percent volumetric water content (\%VWC) observed during drainage trial (means of three replications). (A) Simple mesh. (B) Hanging water column. (C) Wick system. able to remove as much water from arm and bottom positions as from substrate located at the center (bottom, arm, and center had an average of $37.2 \%, 36.7 \%$, and $26.8 \%$ VWC $2 \mathrm{~h}$ before irrigation, respectively). Substrate moisture appears to have established equilibrium more quickly and at somewhat lower $\%$ VWC with the hanging water column $(\approx 12 \mathrm{~h}$ after irrigation) compared with the mesh system at the same locations (arm and center did not reach equilibrium, thus \%VWC was continuously declining).

The best results were obtained with the wick system (Fig. 2C), which came into equilibrium more slowly than the hanging water column system (18 and $12 \mathrm{~h}$, respectively) but maintained substrate moisture levels more uniform between all positions than did the other two systems (Fig. 7C). The difference in \%VWC between bottom and center positions were $27.8 \%, 9.9 \%$, and $4.7 \%$ for simple mesh, the hanging water column, and wick systems, respectively. Also, \%VWC was significantly lower at equilibrium and less variable ( $30 \%$ to $35 \%$ VWC) than that of the other two systems (26\% to $37 \%$ VWC for the hanging water column and $28 \%$ to $53 \%$ VWC for simple mesh) and thus was considered more characteristic of deep loamy sandy soils (Rab et al., 2010). Sandy soils have relatively large pores and drain freely (Morgan et al., 2001).

\section{Conclusion}

The majority of root observation devices reported in the literature allow limited observation (one to two ports only) regardless of whether these rhizotrons force root growth through narrow spaces or are installed in natural settings. Although similar in shape to the star-shaped rhizotron described by Wright and Wright (2004), the rhizotron described here has several additional advantages. Roots can be observed in each window one at a time, thereby minimizing root exposure to light during measurements. Independent portal operation is very useful in experiments that require root sampling such as for biochemical analysis. The elevated design places roots at a convenient height for visualization. Drainage is efficient, assuring removal of excess water, thus creating conditions close to those in-ground. Finally, PVC windows are safer than glass, insulate the root zone, and are opaque to sunlight.

The rhizotron described here also minimizes physical restriction to normal root growth, development, and distribution and offers eight viewing profiles, greatly enhancing the study of a root system as a whole. The structure is sturdy enough to support a large substrate volume and can be increased in size to accommodate larger root balls or for experiments of longer duration. With the large rhizotron size, the root system developed by L. japonicum after 5 months was not restricted. Roots visible in the viewing ports had good spatial separation, improving root analyses by digital photography or visual observation. 
Rhizotron facilities usually devise methods for drainage (Huck and Taylor, 1982; Karnok and Kucharski, 1982; Soileau et al., 1974), but persistence of perched water tables has not been appraised or addressed in previous studies of root chamber models (James et al., 1985; Ugoji and Laing, 2008; Wright and Wright, 2004). Nonetheless, unimpeded drainage, especially removal of perched water tables, was a critical objective for the rhizotrons described here. Soil moisture sensors were installed to evaluate the effectiveness of the evaluated methods for removing perched water. With removal of the perched water table, the system provides good simulation of an in-ground soil environment. Easy adaptations to this model can enable it to be used in split root trials or as a lysimeter. The rhizotron can be divided in the center frame by the same expanded PVC board used on the doors and provides up to four different quadrants for split root studies. These rhizotrons can thus be used to investigate the effect of diverse variables on root growth. Examples could include partial root drying, soil texture (Bengough et al., 2006), fertilizers (Boukcim et al., 2006; Drew, 1975), or agricultural chemicals (Tsakaldimi and Ganatsas, 2006).

\section{Literature Cited}

Bengough, A.G., M.F. Bransby, J. Hans, S.J. McKenna, T.J. Roberts, and T.A. Valentine. 2006. Root responses to soil physical conditions; growth dynamics from field to cell. J. Expt. Bot. 57:437-447.

Bilderback, T.E. and W.C. Fonteno. 1987. Effects of container geometry and media physical properties on air and water volumes in containers. J. Environ. Hort. 5:180-182.

Bland, W.L., M.A. Mesarch, and J.E. Wolfe. 1990. A controlled-temperature rhizotron. Crop Sci. 30:1142-1145.

Boukcim, H., L. Pagès, and D. Mousain. 2006. Local $\mathrm{NO}^{-}$or $\mathrm{NH}^{+}$supply modifies the root system architecture of Cedrus atlantica seedlings grown in a split-root device. J. Plant Physiol. 163:1293-1304.
Boukcim, H., L. Pages, C. Plassard, and D. Mousain. 2001. Root system architecture and receptivity to mycorrhizal infection in seedlings of Cedrus atlantica as affected by nitrogen source and concentration. Tree Physiol. 21:109-115.

Busch, J., I.A. Mendelssohn, B. Lorenzen, H. Brix, and S.L. Miao. 2006. A rhizotron to study root growth under flooded conditions tested with two wetland Cyperaceae. Flora 201:429-439.

Calfee, L.R. 2003. Post-transplant root production, mortality, and periodicity of landscape-sized shade trees. Diss., Virginia Polytechnic Institute and State University, Blacksburg, VA.

Devienne-Barret, F., C. Richard-Molard, M. Chelle, O. Maury, and B. Ney. 2006. Ararhizotron: An effective culture system to study simultaneously root and shoot development of Arabidopsis. Plant Soil 280:253-266.

Drew, M.C. 1975. Comparison of the effects of a localized supply of phosphate, nitrate, ammonium and potassium on the growth of the seminal root system, and the shoot, in barley. New Phytol. 75:479-490.

Gallandt, E.R., G.G. Raitt, and P.K. Fay. 1990. An inexpensive rhizotron for teaching weed biology. Weed Technol. 4:663-665.

Garrigues, E., C. Doussan, and A. Pierret. 2006. Water uptake by plant roots: I-Formation and propagation of a water extraction front in mature root systems as evidenced by $2 \mathrm{D}$ light transmission imaging. Plant Soil 283:83-98.

Huck, M.G. and H.M. Taylor. 1982. The rhizotron as a tool for root research. Adv. Agron. 35:1-35.

James, B.R., R.J. Bartlett, and J.F. Amadon. 1985. A root observation and sampling chamber (rhizotron) for pot studies. Plant Soil 85:291-293.

Karnok, K.J. and R.T. Kucharski. 1982. Design and construction of a rhizotron-lysimeter facility at the Ohio State University. Agron. J. 74:152-156.

McDougall, W.B. 1916. The growth of forest tree roots. Amer. J. Bot. 3:384-392.

Metcalfe, D.B., P. Meir, and M. Williams. 2007. A comparison of methods for converting rhizotron root length measurements into estimates of root mass production per unit ground area. Plant Soil 301:279-288.

Misra, R.K. 1999. Root and shoot elongation of rhizotron-grown seedlings of Eucalyptus nitens and Eucalyptus globulus in relation to temperature. Plant Soil 206:37-46.
Morgan, K.T., L.R. Parsons, and T. Adair Wheaton. 2001. Comparison of laboratory- and fieldderived soil water retention curves for a fine sand soil using tensiometric, resistance and capacitance methods. Plant Soil 234:153157.

Rab, A., P. Fisher, N. Robinson, M. Kitching, C. Aumann, M. Imhof, and S. Chandra. 2010. Plant available water capacity of dryland cropping soils in the south-eastern Australia. 19th World Congress of Soil Science, Soil Solutions for a Changing World, Brisbane, Australia.

Schoene, G. and T. Yeager. 2006. Influence of nitrogen application rate on the magnitude of root and shoot growth flushes of Viburnum odoratissimum Ker-Gawl. Plant Soil 284: $121-128$.

Silva, D., D. Cox, and R.C. Beeson, Jr. 2011. Development and evaluation of a large-volume rotary root separator. HortScience 46:676-678.

Soileau, J.M., D.A. Mays, F.E. Khasawne, and V.J. Kilmer. 1974. Rhizotron-lysimeter research facility at TVA, Muscle-Shoals, Alabama. Agron. J. 66:828-832.

Spomer, L.A. 1980. Container soil water relations: Production, maintenance, and transplanting. J. Arboric. 6:315-320.

Stepniewski, W., S.R. Pezeshki, R.D. Delaune, and W.H. Patrick. 1991. Root studies under variable redox potential in soil suspensions using laboratory rhizotrons. Vegetatio 94:47-55.

Taylor, H.M. and W. Bohm. 1976. Use of acrylic plastic as rhizotron windows. Agron. J. 68: 693-694.

Tsakaldimi, M.N. and P.P. Ganatsas. 2006. Effect of chemical root pruning on stem growth, root morphology and field performance of the Mediterranean pine Pinus halepensis Mill. Sci. Hort. 109:183-189.

Ugoji, E.O. and M.D. Laing. 2008. Rhizotron studies on Zea mays L. to evaluate biocontrol activity of Bacillus subtilis. World J. Microbiol. Biotechnol. 24:269-274.

Wiese, A.H., D.E. Riemenschneider, and R.S. Zalesny, Jr.. 2005. An inexpensive rhizotron design for two-dimensional, horizontal root growth measurements. Tree Planters' Notes 51: 40-46.

Wright, A.N. and R.D. Wright. 2004. The Horhizotron $^{\mathrm{TM}}$ : A new instrument for measuring root growth. HortTechnology 14:560-563. 